\title{
Power Play and Performance in Harajuku
}

\author{
Amelia Groom \\ University of Technology, Sydney
}

\begin{abstract}
This article analyses the structures and implications of Japan's contemporary street fashion cultures, primarily those of Harajuku. Using Roland Barthes' analogy of dress and dressing it situates the radical subcultural styles within traditional Japanese aesthetics and in a wider history of fashion. Examining various motifs from kawaisa to uniforms, cross-dressing, masks and the politics of second-hand fashion, it deals with theories of authenticity, appearance and agency.
\end{abstract}

\section{Keywords}

Japanese fashion, Harajuku, performance, identity, subculture

\section{Introduction}

This study will outline a brief history of Harajuku street fashion since the late 1970s, focusing on the interplay of invention and convention, authenticity and artifice, innovation and imitation. Borrowing from De Certeau's tactical everyday resistance and Roland Barthes' structuralist application of dress and dressing in fashion, it will consider the ways in which the players in Harajuku change the meaning of available dress objects in the process of their individual dressing.

The article is informed by observational research done in Tokyo in 2006 and 2007 and woven throughout the text are insights from a broad range of artists and writers. The chapter Origins and Spread looks at the question of where fashions come from and how they are circulated. Academic accounts to date have tended to overemphasise the process of fashion imitation by the lower classes followed by aversion by the elite, when in fact the operation is more complex. The purity of subcultural styles should also not be overstated, and examination of Harajuku shows the process of fashion origin and spread to be highly layered and multi-directional. Of particular note here is the new model of fashion media that came out of Japan's youth fashion cultures of the 1990s whereby professionally styled editorial shoots were replaced by images of 'normal' people in their self-styled creations. 
In considering the relationship between individuality and conformity, the study turns to Pierre Bourdieu's account of taste and distinction and recognises the inherent paradox of fashion, whereby it forms a statement of criticism as well as a shared expression of a desire for sameness. When it comes to so-called rebellious subcultural fashion, the process of commercial recuperation can be particularly problematic, but as Harajuku dress-ups are often self-consciously and retrospectively imitative they don't face this predicament of authenticity that the western subcultures they borrow from did. The highly subjective, personal and sensual relations people have with clothing is also necessarily acknowledged here.

In the chapter Clothes Wear Us, the discussion of the potential political dimensions of fashion opens up an examination of performativity and identity in Harajuku, particularly with regards to gender politics. Another way to consider the interplay of individuality and conformity in dress is to look at uniforms in contemporary Japan, in particular the phenomena of the fetishised schoolgirl uniform. Kogals are read as subjecting themselves to the paedophilic male gaze, while also evading certain structures of power by creating their own sphere of inclusion. Similarly, in the chapter Empowered Cuties?, kawaii is read on one level to be making young women present themselves as naive and vulnerable, but also to be offering them a space for rejecting the adult responsibilities they are expected to aspire to. This part of the thesis owes much to McVeigh's inquiry into uniforms in Japan and Sharon Kinsella's extensive work on Japanese cuteness.

Forming several links between traditional Japanese dress and contemporary fashion, I look at a deconstructionalist approach to dress and dressing, whereby usually hidden structures of dress are brought to the surface. Interrogating the fashion system from within that system, these teens in Harajuku bring into question the very meaning of dress. Their foregrounding of artifice is situated in a wider urge for blatant theatricality that is traced in several areas of Japanese art and life, and the aestheticising of impracticality is seen as overcoming any pretence of naturalness in fashion, and thus regaining a type of honesty. The final chapter, New Face, New Life, offers a consideration of the mask in Japanese culture and of performative fashion as a type of masking. Rather than something that merely hides, examples of masking in Japanese culture are used to define the mask as something that reveals while it conceals, possessing a unique capacity for truthfulness.

I do not wish to delve into myths of Japanese uniqueness or some constructed cultural collective subconsciousness, nor do I have any pretence of being able to deal with a unified or continuous 'Japan'. Points of consideration span myriad examples within this thing we call Japan, and what follows is a series of trajectories tracing a thread of ideas about self-consciously eccentric bodily presentation. Rather than being treated as some 
strange, exotic enclave, the radical fashion of Harajuku is used for thinking about wider ideas relating to the possibilities (and limitations) of resistance through dressing. In the broadest sense the study comes from my longstanding curiosity about the primal human urge towards body adornment and the relationship between appearance and truth.

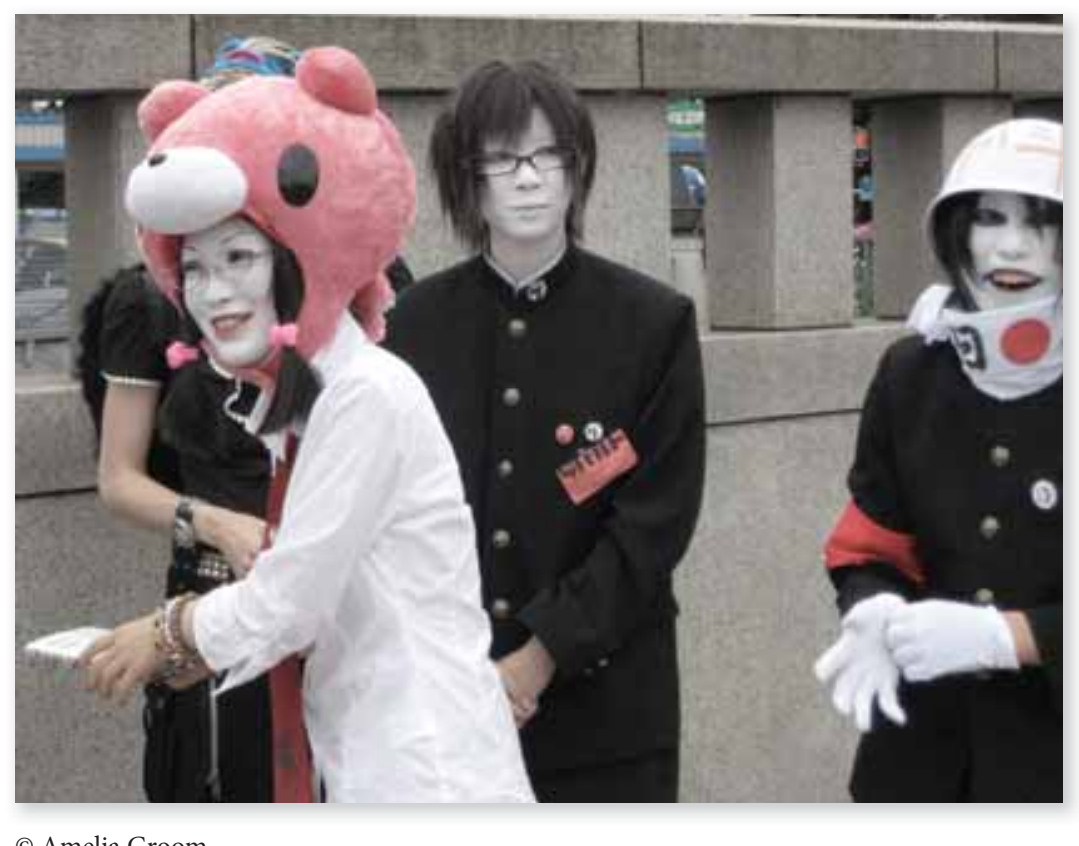

(C) Amelia Groom

\section{Chronicle of Costumes}

Underlying this study of Harajuku street fashion is the idea that clothing has less strictly utilitarian value than is commonly attributed to it. Thomas Carlyle's Professor Teufelsdröckh told us in the mid-nineteenth century that 'The first purpose of clothes was not warmth or decency, but ornament' and, 'among wild people we find tattooing and painting even prior to clothes. ${ }^{1} \mathrm{He}$ found unlikely resonance with a certain supercilious feline in Meiji Japan, Natsume Sōseki's nameless narrator in his novel I Am a Cat who cites Teufelsdröckh and muses that 'human history is not the history of flesh and bone and blood, but a mere chronicle of costumes.'

From 1977-1998 the main street in Harajuku, Omotesandō, was declared hoko ten ('pedestrian haven') and cars were banned every Sunday. One of the earliest style 
tribes that arose in the area was the takenoko-zoku ('Baby Bamboo Shoots Tribe'), characterised by garish-coloured shiny robes and cheap accessories like plastic whistles, long fake-pearl necklaces, nametags, stuffed animals stitched to the ensembles, and kung fu shoes. Performing choreographed dance moves for hours on end at Yoyogi Park, they invented a vibrant sphere of inclusion where their constructed self-image made them intensely visible, but also kept them distanced from their surroundings and from the audiences they drew. Quickly becoming a popular tourist attraction, they translated the state of being under perpetual scrutiny into the pleasure of being seen.

Like the many Harajuku subcultures that came after them, their playful interpretations of place and commodities formed tactics of resistance, avoidance and escape. The radicalism of the aesthetic play in Harajuku no longer exists at the same intensity as it did in the hoko ten years, but the area remains a unique site of communal spectacle where all are positioned under intense public surveillance, and the separation between performers/spectators is dissolved. In accordance with Mikhail Bakhtin's carnival, the ritualized masquerade temporarily transgressed the austerity of daily life with an inversion of everyday hierarchies and social boundaries. ${ }^{3}$

With genres enacted in a self-reflexive masquerade without any regard for authenticity, Harajuku fashion destabilises the idea of a transhistorical body or naturally occurring agent beneath the surface. We constitute ourselves as hippy, hillbilly or hiphop simply by looking the part: these subcultures were not grown organically in Japan but were adapted retrospectively with obsessive attention to details of dress, music, dance moves and whatever other stylistic elements, making evident that identity is nonessential. So many niche fashions have never existed side by side as in the hyperreality of Harajuku, where trendy teens celebrate the superficiality of their posed identities without denying that that is all they are.

One example is the early 2000s trend for surfer style which saw an exponential consumption of peroxide, fake tan, faux hibiscus flowers and bright blue contact lenses, rendering thousands of Japanese teens caricatures of Californian beach babes - but also something entirely new. Nothing is purely innovative or imitative and the process of repetition always introduces an element of metamorphosis. Consumers don't take things on passively or uncritically, but relocate signs from their original contexts and transform their meanings in a chaotic bricolage where the distinction between artificial and authentic is extraneous. Their imitative reproduction of images is a methodically precise process not unlike that of the Zen calligrapher: in the words of Rupert Cox, 'It is not possible to make a clear distinction between the authenticity of an aesthetic original

3 Bakhtin, Rabelias and his World. 
and the authenticity of its copy, when the culture of the Zen arts is about reproduction and repetition as a valued cultural aesthetic'. ${ }^{4}$

\section{A Thing to Wear}

According to Roland Barthes, fashion is a system comprising dress, the social reality independent of the individual, and dressing, which takes place when the subject actualises on their body the inscription of dress. ${ }^{5}$ He aligned this broad structuralist model with Ferdinand de Saussure's langue and parole directions of language - the former being the social institution that constitutes the normative standard, the latter the individual manifestation. The fashion structure does not simply hang dress objects on passive bodies; consumers must be active in dressing themselves. The innovative dressers in Harajuku aren't rejecting the prescribed dress available to them, but adopting, adapting and altering, and thus symbolically subverting their position from the inside. Dressing - the individual use of the dress object - can lend a silent political dimension to everyday practice. In the act of dressing, like Michel de Certeau's walking, ${ }^{6}$ authority is decentred and we are the narrators of our own experiences; but as the structure of the city restricts how we can navigate it, so too are we limited by what dress objects are available to us. We are at once fashioning the world and fashioned by it.

Changing the meaning of the dress object in the process of their dressing, Tokyo's street fashion innovators irreverently but seamlessly combine traditional Japanese dress (including kimonos, obi belts, kanzashi hair pins and geta sandals), modern avant-garde Japanese couture, contemporary and retro Western fashion, and completely new trends using handmade and re-assembled second-hand fashion. Their hybridity of images demonstrates the perceived Japanese skill at combining novelty and tradition, East and West, without compromising an essential identity. The styles are too eclectic to be categorised as a single subculture, but as a whole Harakuju fashion is best described as 'layered', which suggests that their bodies and identities are polyvalent works in progress requiring a patchwork of meanings.

Continually borrowing from Japan's rich visual heritage, the street fashion is as evolutionary as it is revolutionary. Putting the banal, beautiful and grotesque side by side, their radical self-presentation can be situated alongside the elaborate costuming that has existed for many centuries in Japan, like the geisha's extravagant, artificial beauty or the samurai's complex armor. The basic adult kimono ( $k i$ mono meaning 'a thing

\footnotetext{
Cox, The Zen Arts: An Anthropological Study of the Culture of Aesthetic Form in Japan, p. 232

Barthes, 'History and Sociology of Clothing: Some Methodological Observations', p. 8.

De Certeau, The Practice of Everyday Life.
} 
wear') comes in two sizes - man and woman - and has never deviated from the basic, untailored $\mathrm{T}$ shape that was introduced in the 8th Century. Rather than emphasizing the human form and striving for the ideal figure, as Western dress has done, the kimono has its own structure and silhouette that is independent of the individual wearer. It retains its own elemental geometric form with little regard for the body's biological contours, an approach that can be traced in the work of contemporary Japanese fashion designers who have become known for voluminous, one-size-fits-all, layered creations.

\section{Origins and Spread}

Change in fashion has often been explained as a 'trickle-down' effect of class imitation followed by class aversion. But wearing the latest style is no longer a privilege reserved for the upper strata, and mutations in fashion cannot be understood as a simple process of diffusion from the elites to the masses. Some have presented an alternate model where subcultural innovations 'bubble-up' until they are adapted by emulating commercial bodies. Ted Polhemus, for example, boldly asserts that without the teddy boys, beats, rockers, rude boys, mods and numerous other stylistic categories he looks at, 'most of us would be left without anything to wear.' Such accounts, however, overstate the influence and purity of street styles. Fashion is never merely a cannibalistic emulation or artificial promotion of new commercial trends and the relationship between fashion and so-called 'anti-fashion' is a continually dialectical one.

There is also no coherent fashion mainstream, but simultaneous fashion systems for different cultures, classes, lifestyles, age groups and localities. Some 'trickle down', some 'bubble up', some move horizontally, some remain more or less where they started. Tastes are not simply dictated and we should acknowledge the complexity and idiosyncratic sensual significance of material things in people's lives. Clothes are invested with both individual and collective facets of identity, memory and imagination. Beyond social competition, fashion comes from the primal pleasures of performance, play, creation and destruction. As Barthes tells us, it 'can be part of a dress object that has been artificially elaborated by specialists at any one moment', and, 'at another moment, it can be constructed by the propagation of a simple act of dressing that is then reproduced at the collective level'. ${ }^{8}$ 


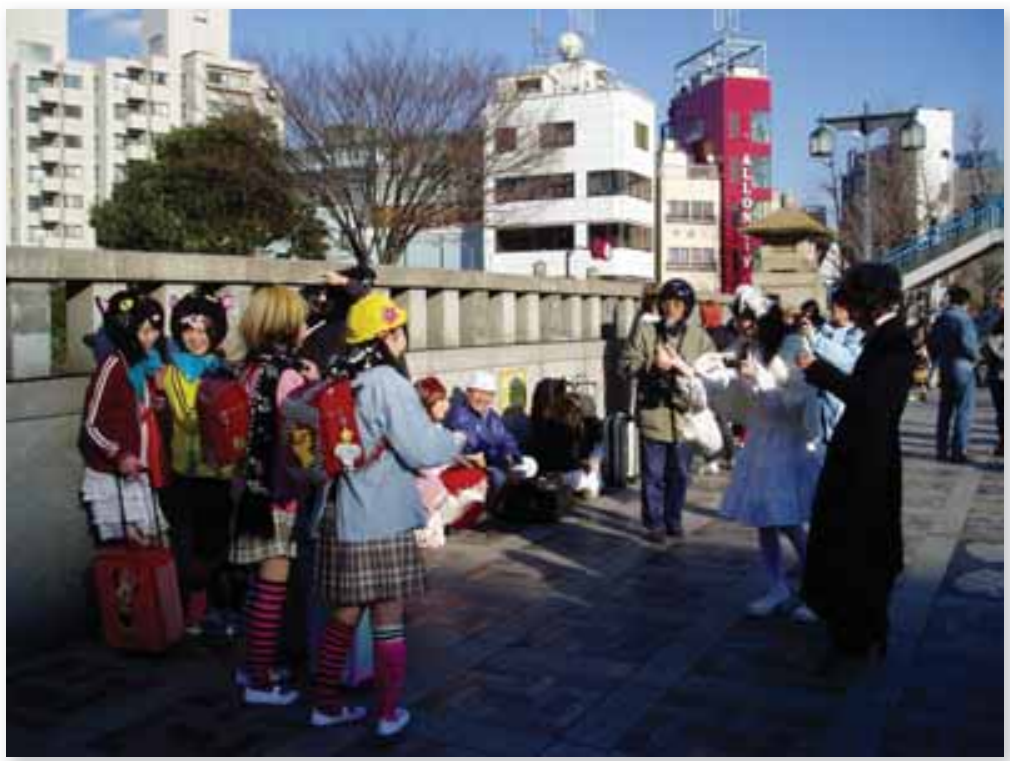

(c) Amelia Groom

Because Harajuku fashion is less about what one wears than how one wears it, the dresser commonly supersedes the designer in generating style directions. While the emphasis on DIY practice means the individual has the agency to prescribe new meanings to things, their fashion system should not be seen as an enclave of pure innovation outside the wider power structures. Fashions often quickly percolate from the minority groups of predominantly high-school students up to global commercial bodies who reproduce their individual acts of dressing, and the Harajuku players remain very much bound up in Japan's systems of hyper-consumerism.

Magazines with styled editorial shoots once significantly influenced the direction of fashion in Japan, but today teenagers look at themselves represented in fashion media, wearing their own creations. According to Sharon Kinsella, the teen-oriented street style magazines that appeared in the 1990s established unprecedented interaction with their readers, inviting the young schoolgirls to their offices where they provided lounge areas and purikura ('print club') sticker photo booths. Heart Candy magazine recruited 18- to 20-year-old girls as editorial staff and the editor in chief was $23 .{ }^{9}$ In these publications and their successors, fashion imagery consists predominantly of self-styled people. In FRUiTS - the monthly Japanese street fashion magazine founded in 1997 by Shoichi Aoki to document the exploding street fashion movement - there is very little advertising and the only copy is the individual's name and outfit details, giving the full agency to the wearer.

9 Kinsella, 'What's Behind the Fetishism of Japanese School Uniforms?', p. 232. 
Yuniya Kawamura describes how the relationship between producer and consumer is redefined in Harajuku, where most of the shops at the time of her research were run by young artists and students who started their own labels without any formal training. ${ }^{10}$ She also recounts how the salesgirls at the 109 department store in Harajuku's more flashy and commercial neighbouring suburb Shibuya are major players in creating new fashion sensibilities and can become iconic karisuma tenin ('charismatic salesgirls') with celebrity status. It is not unusual for fashion houses to employ karisuma tenin as forecasters or designers, indicating that their ideas have greater currency than formal skills. These teens are positioned as the designers, merchandisers, salespeople, stylists, models, marketers, disseminators and consumers of their own fashion.

\section{Individual Conformity}

The technology of conformity in Tokyo, the world's most populated metropolis, fosters the fantasy of rebellion in Harajuku fashion. People everywhere look to be different only within permitted social parameters, but according to Donald Richie the dual existence of conformity and individualism is vital in Japan because of the emphasis on group identity. Each new fad registers a small criticism of whatever they wore before and this sort of small protest is the kind of criticism most popular in Japan, he writes: 'It is safe and yet, for a brief time, lends a feeling of individuality.' ${ }^{11}$ In many other societies the mischievous eccentricity of Harajuku would be less subversive, and thus wouldn't have come to exist at the same extreme. Because of the conformative nature of dress in Japan, the intensity of the pleasure in the individualistic operation of dressing is heightened.

According to Pierre Bourdieu, taste is about distinction: a system of social organisation that ensures a perpetually unequal distribution of power. Aesthetic stances legitimate social differences and are 'opportunities to experience or assert one's position in social space.. ${ }^{12}$ The need for distinction, he argues, means that there is an ongoing battle in any field between those who want to defend the traditions of the field, and the newcomers who want to render the established values obsolete. The field of fashion is one of rapid transience where things change for the sake of change and 'the permanent struggle within the field is the motor of the field. ${ }^{13}$ In the surveys Bourdieu conducted shortly after May 1968, he recalled that the 'avant-garde newcomers' of the Paris left bank spoke of fashion using the language of politics, saying, 'fashion has to

\footnotetext{
Kawamura, 'Japanese Teens as Producers of Street Fashion', p. 792.

11 Richie, Tokyo: A View of the City, p. 72.

12 Bourdieu, Distinction: a Social Critique of the Judgement of Taste, p. 57.

13 Bourdieu, 'Haute Couture and Haute Culture', p. 135.
} 
be brought on to the streets', and 'haute couture should be within reach of everyone.. ${ }^{14}$ Today Harajuku may be the site where this ideal has manifested most visibly.

Fashion's greatest paradox is that it forms a statement of criticism as well as an expression of the desire for sameness. Anti-fashion does not challenge fashion per se; it shakes up the structure but fashion can always absorb it. In denouncing their opposition to fashion's dictums, subcultures have needed to be aware of the tastes they were avoiding, and always developed their own identifiable styles, often transforming masssanctioned tastes in the process. Anti-fashion statements that have sought to appear beyond concern with the frivolity of appearance could not evade being analysed in terms of the language of dress. We cannot be beyond dress, as we cannot refuse language, but in the everyday act of dressing we can become users who change established meaning and usage. Harajuku fashionistas are using their youth and inexperience in the field to their advantage by constructing a whole new value system.

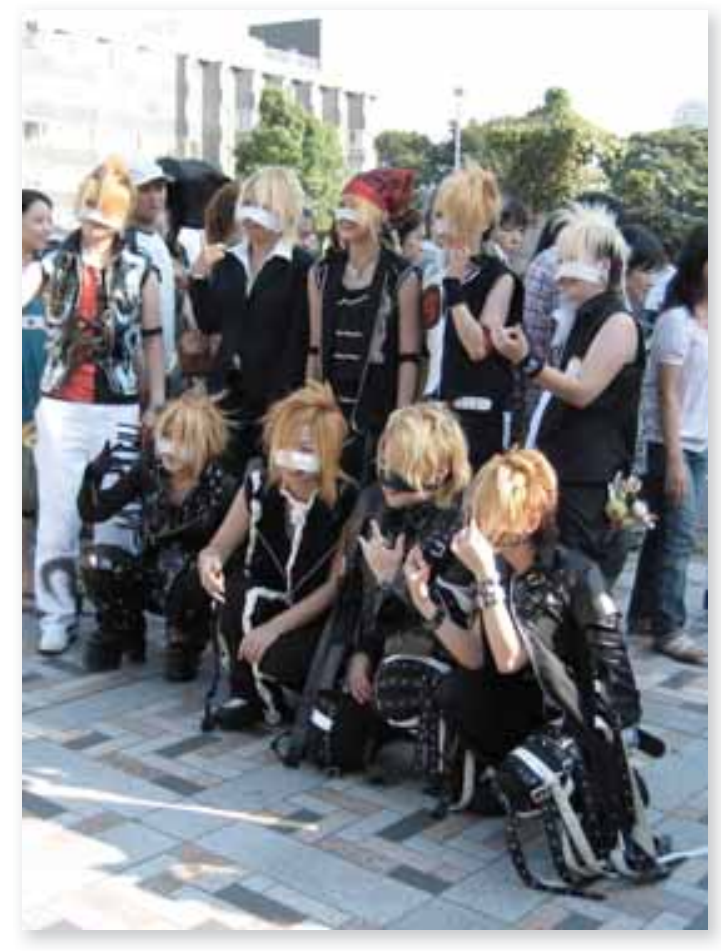

So-called non-conformist countercultures often appear from the outside to be clones of one specific stylised interpretation of 'rebellion' - a nonchalance that is carefully constructed to be read as nonchalance. (Photograph by Amelia Groom).

14 Bourdieu, 'The Metamorphosis of Tastes', p. 113. 
The subcultures analysed by Dick Hebdige had the ability to subvert, revalorise and disrupt, but they were 'inextricably bound up with the process of production, publicity and packaging which must inevitably lead to the defusion of the subculture's subversive power. ${ }^{15}$ The notion is that once the symbols of counter-cultural resistance are repackaged and sold by commercial bodies, they are stripped of any revolutionary potential. The process of recuperation has been seen as presaging the eminent demise of every fringe culture by sanitising, commodifying, and making widely available their ideas and stylistic identity.

But in Harajuku the process is different. The boundary between authentic resistance and commercial recuperation does not exist, and their outrageous styles are often hugely commercially successful from the outset. Journalists, designers, manufacturers, forecasters, retailers and pop stars from around the world keep a close eye on Harajuku - and the business magazine WIRED has had a regular column, Japanese Schoolgirl Watch, for a number of years, trying to keep track of their fads. While Western post-war subcultures, including ironically well-marketed ones, have condemned materialism in the name of 'individuality', Harajuku teenagers are unapologetic about the fact that their subcultural capital requires ongoing consumption.

Youth subcultures started in Japan, like elsewhere, when generational awareness emerged in the young and their increased spending was recognised by marketing industries. Harajuku style is entwined with entrepreneurship and expansion and the teens have no delusions or pretensions of fighting capitalism. They are aware that a lot of their radical innovations will be recuperated into the mainstream, but because their style is more about dressing than objects of dress, a level of agency is retained. The diffusion of their innovations does not dilute the symbolic power of their style because they believe in change for the sake of change. They are playing masquerade with the imagery of past subcultures that are already recuperated, and don't have the urgent preoccupation with the illusory dream of insurgence found in Western subcultures.

According to Kawamura, Harajuku street style identity is never political or ideological, but simply innovative fashion that determines group affiliation. ${ }^{16}$ In a similar vein, Amy Spindler wrote in the New York Times that there are no politics behind the Tokyo fashion movements: 'The punk movement, when it came, was only about fashion. The hip-hop movement has nothing to do with rebellion. Boystyle has nothing to do with women's rights. If you ask the girls why they're wearing it, it's because "it's cute". ${ }^{17}$ It is true that in Harajuku images are taken on as though in quotation marks and incongruity is of

5 Hebdige, Subculture: The Meaning of Style, p. 95.

16 Kawamura, op. cit., p. 758.

17 Spindler, 'Do You Otaku?'. 
little concern as there is no fixed ideological commitment - but comparing Harajuku style to the past Western subcultures from which it borrows images is limiting because power and rebellion function differently today, and have always functioned differently in Japan.

Fashion is often set up as a non-political realm but street style is always politically charged, even when it is grounded on a thriving commercial foundation. Open rebellion is discouraged in Japanese culture, but the teens in Harajuku have a quiet, indirect and private resistance, and to dismiss them as mindless slaves to consumerism is to overlook the fact that while we are socially determined, 'we consistently search for the crevices in culture that open to us moments of freedom. ${ }^{18}$ Fashion, as the medium between the body and the public, allows individuals to think about themselves as subjects in the social world. If power should be viewed, as Foucault argues, 'in its ultimate destinations, with those points where it becomes capillary' ${ }^{19}$ so then should our tactics of resistance, which can be located within the most everyday actions. Something as capillary as a man going about his urban life in a crème skirt and poncho, for example, can be tactical in destabilising the daily masquerade of gender ...

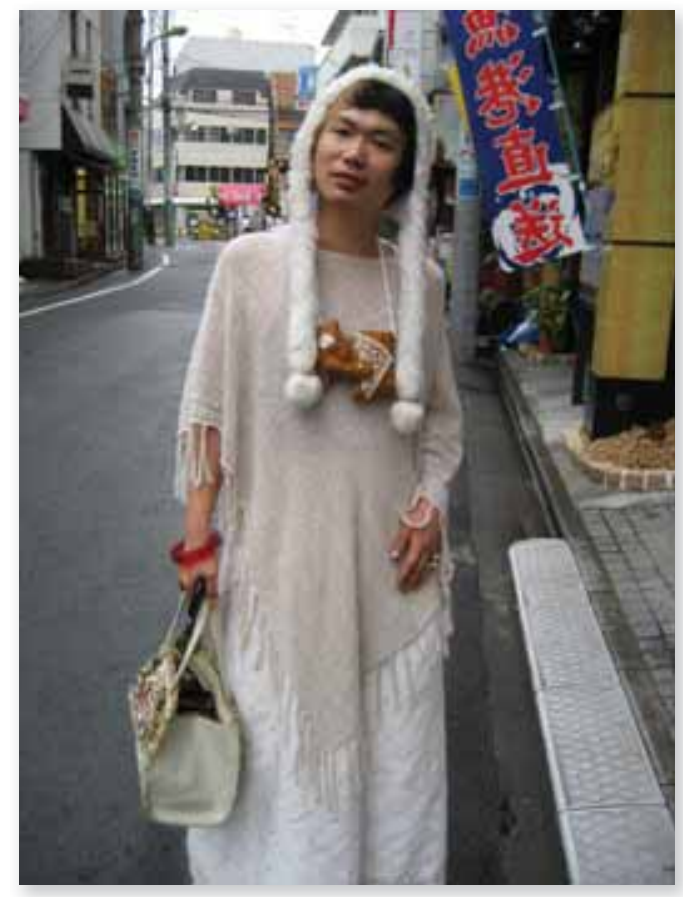

(C) Amelia Groom

18 Wilson, 'Feminism and Fashion', p. 213.

19 Foucault, 'Lecture Two', p. 96. 


\section{Clothes Wear Us}

The performativity of male and female identity is foregrounded in the playful dress-up culture of Harajuku. Valerie Steele writes, 'pity the poor man who wants to look attractive and well dressed, but who feels that by doing so he runs the risk of looking unmanly, ${ }^{20}$ but no such pity should be granted to men in Harajuku. Besides blatant cross-dressing, which is not uncommon, men in Tokyo's youth fashion districts are at great liberty to embrace the expressive possibilities of fashion. They are often meticulously groomed with aberrant clothing, haircuts and even make-up. Shoichi Aoki launched TUNE magazine in 2004; with the same premise and format as his FRUiTS publication it is dedicated specifically to male avant-garde street fashion and shows that men's dressing in trendy districts like Harajuku is only marginally less dramatised than that of their female counterparts.

There is no taboo that transgresses all circumstances for everyone across all cultures at all times. One of several women around the world who caused outrage for being 'impostors of men', Emma Snodgrass was arrested in Boston in 1852 for wearing pants. By the 1930s women in trousers were still shocking for many but becoming increasingly chic; and today it is invisible. Vivienne Westwood worded it well: 'it's just a question of adjusting the eyes - it's only perverse because it's unexpected.21 Westwood, who is revered in Harajuku, is one of a select few designers who have tried a number of times to introduce male skirts, but although many gendered rules for dressing now amount to little, men still can't wear skirts inconspicuously.

While men once coveted exuberance in dress, since the Eighteenth Century western male fashion has been increasingly restricted in silhouette. Skirts/dresses are the most clearly gender-specific clothing we have (though the male anatomy is actually better built for them), which might relate to men's aversion to concealing the phallic suggestion of power, or a Freudian fear of castration. The man pictured above in the crème skirt ensemble possesses stronger implications than the overt exaggeration of drag. He is not a hyperbolic image of a woman, he is just comfortably wearing unbifurcated attire - like the kimonos, kilts, caftans, sarongs, tunics, grass skirts and togas that have been worn by men throughout history, and are still worn frequently in many parts of the world. Through his dressing he shows that our prescribed gender aesthetics are arbitrary.

This non-essentialness of gender is demonstrated in Virginia Woolf's Orlando: A Biography. Initially feeling no different after transforming from man to woman, we read, once Orlando has been wearing skirts for a while, 'a certain change was visible.'2 She finds

20 Craik, Faces of Fashion: Cultural Studies in Fashion, p. 176.

21 Wilcox, Vivienne Westwood, p. 24.

22 Woolf, Orlando: A Biography, p. 171. 
herself being treated differently and becoming more modest, more vain, more fearful of her safety. 'It is clothes that wear us and not we them, the narrator tells us, 'we may make them take to mould of arm or breast, but they mould our hearts, our brains, our tongues to their liking. ${ }^{23}$ There is no inherent male or female; there is only costume. This is certainly the case with the Japanese geisha (from gei 'performing arts' and sha 'person'), who undergoes elaborate rituals of preparation before appearing and behaving as a geisha. Her face is painted with a thick white paste, and on the blank surface her eyebrows are drawn in black, high on the forehead, and her lips are painted in deep red, smaller than her natural mouth. Her hair is painstakingly arranged with a special oil so as to resemble a sculptural wig, and her every movement is deliberated and stylised. She is an unapologetically synthetic beauty, a masquerade of sensual femininity. In the words of James McCormick 'she is a costume that fits a woman rather than a woman who fits a costume. ${ }^{24}$

The popular Harajuku subculture Lolita draws on a highly feminised aesthetic derived from Victorian dolls with ribbons, lace, embroidery, bonnets, corsetry, frills, and hair in ringlets. Becoming a Lolita is laborious and the end result is so constructed as to indicate the performativity of all female identity. Unlike in the post-war Western subcultures, such as those analysed by Hebdige, it is predominantly females who drive the Lolita fashion culture and obtain the most visibility. There are, however, a significant number of males in Harajuku who adopt the look, complete with bloomers, bows and stockings. Mana-Sama is the most famous of a number of male celebrities who wear the Lolita style in their daily lives. His fashion label Moi-même-Moitié sells the sub-categories of Elegant Gothic Lolita (EGL) and Elegant Gothic Aristocrat (EGA), both centred on androgyny.

Mana-Sama is also famous as the former front man of the influential visual kei band Malice Mizer. Visual kei ('visual type') is a music genre that self-consciously foregrounds an emphasis on visuality, and therefore treats illusion as illusion. Its aesthetic is a combination of traditional Japanese dress with cyber-punk/goth. Like the glam rock and hair metal musical styles often compared to visual kei, there is an emphasis on androgyny and adulation of feminine-looking men. Many male visual kei musicians take on female names and personalities to become cartoon versions of femininity, acting out an idea of womanhood better than the 'real' women who follow in their footsteps. As Judith Butler suggested, in imitating gender, drag implicitly reveals the imitative structure of gender itself'. ${ }^{25}$ All gender, she says, is a form of drag as there is no core 'masculine' or 'feminine' to refer to. In a final twist, female visual kei fans imitate their favourite performers in Tokyo's street fashion and kospure (from cosplay or 'costume play') districts, as women impersonating men impersonating women.

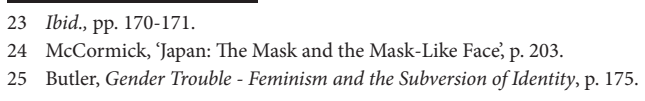

24 McCormick, 'Japan: The Mask and the Mask-Like Face', p. 203.

25 Butler, Gender Trouble - Feminism and the Subversion of Identity, p. 175. 


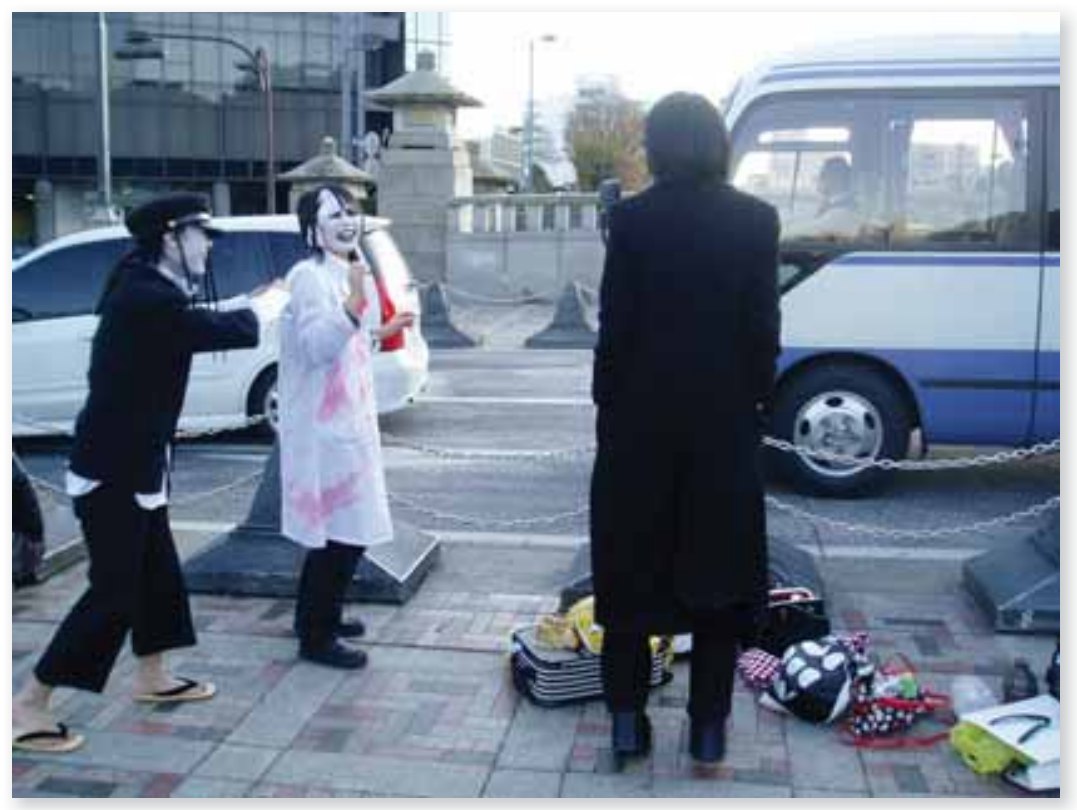

(C) Amelia Groom

\section{Many Forms of Uniform}

Official uniforms were first introduced in Japan as part of its modernisation policy and today they exist with profound salience. Brian McVeigh describes Japan as 'the most uniformed society in the world', where everyone is costumed for their social role and prescribed dress forms unambiguous hierarchies in even the smallest institutions. ${ }^{26}$ Schools in Japan regulate uniforms to varying degrees, but many dictate haircut and style, bags, socks, even underwear. However, like anywhere, students find ways to use the uniform as a platform for building their subjective identity. Far from being viewed as suppressing individuality, McVeigh found in his surveys of high-school students that the uniform can actually determine idiosyncratic expression - when everyone was in the same thing, the individuality of each person was made clearer. ${ }^{27}$ Uniforms make the wearer visible as a member of a group but offer a veil of anonymity since the body is obscured by the instantly recognisable formalised code. The costume play of kospure offers temporary symbolic retreat from the seriousness of official costumes and roles, while simultaneously creating a new stage for group identity and performance, within specified spacial and temporal zones.

26 McVeigh, Wearing Ideology: State, Schooling and Self-Presentation in Japan.

27 Ibid., p. 84. 
As Craik demonstrates, while the uniform's symbolic elements might indicate a desire for control, predictability, authority, discipline, conformity or standardisation, the reality is more nuanced. ${ }^{28}$ The 'informal codes' of the uniform appear frequently in subversive and licentious contexts. While designed to desexualize the body by restricting movement and concealing shape and flesh, they have long been appropriated in fetish cultures. It is not surprising then that the Japanese culture of official dress breeds a unique fetishism of the uniform, the most widespread example being the adult male perversion for the uniformed schoolgirl.

The Japanese sailor-style girls' school uniform is as iconic as the kimono - there are encyclopaedias cataloguing all varieties, several companies produce miniature doll versions, and there's a thriving second-hand market for collectors. Kinsella has discussed the extent of what she calls the 'Japanese schoolgirl mania', which she says peaked in the 1990 s. $^{29}$ At this time men were purchasing phone conversations, company (enjo kosai or 'assisted dating'), and sometimes sex from schoolgirls, usually through specialist agencies. Burusera ('bloomer sailor') shops were selling schoolgirl uniforms, underwear, even gobs of saliva, ${ }^{30}$ and, infamously, their underpants could also be purchased from vending machines.

At this time a new street style emerged in Tokyo, which, according to Kinsella, was a self-conscious response to the media frenzy. Known as kogal (from kogyaru, 'high-school gal'), their fashion sensibility was based on customised school uniforms, salon suntans, streaked and colored hair, rusu sokusu ('loose socks'), heavy eye make-up, painstakingly accessorised and decorated mobile phones, and elaborate nail art. They unbuttoned the tops of their blouses, rolled their sleeves up, wore ties loose and shortened their hemlines, to combine sexual naivety with overt sexiness and turn the connotations of the uniform around. The kogal were self-commodified, subjecting themselves to the adult male gaze but also evading it by creating their own system of inclusion. Their self-image was a reaction to, and depended on, their social visibility.

\section{Subjectivity and Visibility}

While in modern Japan all can have at their disposal a vast array of choice with regard to appearance, this democratic ideal has meant that everyone is burdened with the pressure of an ever-changing spectacularised fashion culture that implies strict surveillance and scrutiny of the self. This permanent, unconscious sense of being visible

\footnotetext{
8 Craik, 'The Cultural Politics of the Uniform'.

29 Kinsella, 'Japanese Highschool Girl Brand'.

30 Ibid., p. 104.
} 
is only superficially escaped by the subcultures of Harajuku, where playful normbreaking bodily presentation is encouraged and made public. Although subcultural identities are negotiated in opposition to an imagined 'mainstream', there is the same self-regulation and omnipresent panoptical scrutiny, imposing an intense pressure to see oneself and be seen in certain ways. In hedonistic Harajuku there is pleasure in power and power in pleasure: there is both 'the pleasure that comes of exercising a power that questions, monitors, watches, spies, searches out, palpates, brings to light; and on the other hand, the pleasure that kindles at having to evade power, flee from it, fool it, or travesty it. ${ }^{31}$

Photography is a central part of Harajuku's fashion culture. The costumed teens take candid and posed photographs of themselves and each other for hours on end with their mobile phones and digital cameras; none of their efforts are left undocumented. The numerous surrounding purikura arcades allow them to stage photo shoots with their desired personas and get instant sheets of miniature photos decorated with their choice of captions and embellishments. Photographers from the various teen street style magazines also spend hours in Harajuku capturing the latest individual artistry of dressing. Their publications form a conversation rather than a monologue because they feature images of pedestrians in their own creations who control how they are represented and are given full credit in the publication. However, the photographers also shape the reality they document. Not only do they distort the representation through selection, exclusion and repetition, but also the very presence of their lens changes behavior. The possibility of appearing in the publications means the amateur models must forever outdo themselves and each other, to be selected for the camera's gaze.

31 Foucault, The History of Sexuality: An Introduction, p. 45. 
New Voices Volume 4

\section{Empowered Cuties?}
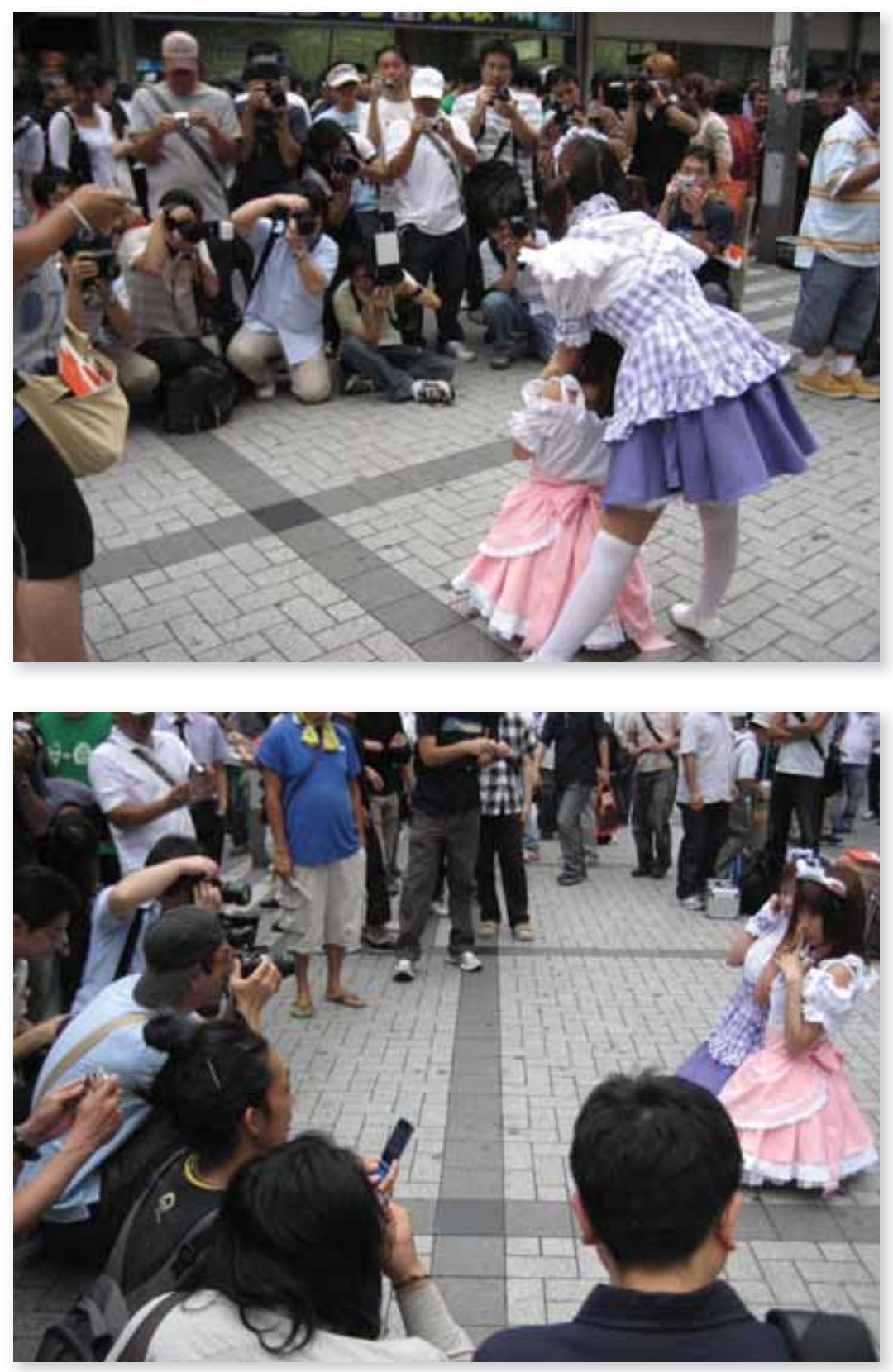

(C) Amelia Groom 
Kawaisa (usually translated as 'cuteness') saturates Japan's visual landscape with bright, juvenile and saccharine imagery, and is particularly prominent in Tokyo's street fashion cultures. Akihabara, known as Tokyo's 'electrical town' and the centre of kospure culture, is home to many meido kafe ('maid cafés') where young female waitresses dressed in maid costumes act as servants for predominantly male patrons. It was in Akihabara that I witnessed these two young girls dressed as matching French maids (one pale pink, one pale purple) in the most blatant enactment of subservience for the fetishised male gaze imaginable. They had drawn a large crowd of men who stood around them peering through their camera lenses as the girls posed in various demure ways with sweet, lobotomized expressions. The more camera lenses that appeared in front of them, the more exaggerated their staging of cuteness became.

Kawaisa often feeds into complex sexual dynamics in Japan, and it is not unusual for child-like demurity to be prominently featured in sexually charged and pornographic images. Young girls who embrace kawaii are often accused of making themselves politically and economically subservient, and reducing themselves to sexualised objects of the paedophilic male gaze. According to Kinsella, being kawaii involves 'acts of self-mutilation, posing with pigeon toes, pulling wide eyed innocent expressions, dieting, acting stupid, and essentially denying the existence of the wealth of insights, feelings, and humour that maturity brings with it. ${ }^{32}$

However, the power dynamics of style are not uni-directional, and kawaii can exist at the level of individual dressing as an everyday tactic of empowerment. Kinsella found in her surveys of Japanese adolescents that they viewed adulthood not as a means of freedom and independence, but a period of restrictions and hard work. It offers a respite from the perceived banality of the adult world, and young women anxious about future subservience, obscurity and drudgery in married life fashion themselves like little girls as a tactic of avoidance. It is a resistance focused on uniqueness, eccentricity, spontaneity, vibrancy and playfulness. They express a 'demure, indolent little rebellion rather than a conscious, aggressive and sexually provocative rebellion of the sort that has been typical of Western youth cultures.' ${ }^{33}$

An aesthetic focused on the feminine, cuteness ignores or outright contradicts Japan's “"male” productivist ideology of standardisation, order, control, rationality and impersonality. ${ }^{34}$ Even the kawaii styles that draw on the most unrealistic sexualised images of women can entail transgression and subversion. The gyaru ('gal') subcultures

\footnotetext{
2 Kinsella, Cuties In Japan.

33 Ibid.

34 McVeigh, op. cit., p. 16.
} 
of the 1990s and early 2000s might be described as 'prostitute chic' with their miniscule hot pants, elephantine platforms and over-dramatized make-up. The look had an incredibly narrow definition of sexiness, but it was also a masquerade that interrogated the line between 'ugly' and 'beautiful' and separated the young girls from traditional values of femininity. It could grant them ownership of their self-image, provide confidence in the male-dominated public sphere where they were encouraged to be modest and acquiescent, and allow strong bonds of female alliance.

\section{The Politics of Reuse}

Publications that cater to the kawaii culture, like Cutie magazine, encourage a DIY approach to fashion and often include sewing or crochet patterns for hand-made designs. This, combined with the celebration of second-hand clothing, makes for a thrift fashion culture that is a respite from the fetishised dictatorial big-name brands that so obsess many metropolitan Japanese. In a country where over forty per cent of the world's luxury fashion is consumed, ${ }^{35}$ this can be read as a political gesture that can interrogate the power structure of fashion.

Immediately behind Omotesandō - where exclusive global couture boutiques glisten side-by-side with armed security guards at the doors - is the independent designer and second-hand fashion district Ura-Hara ('Harajuku's back streets'). Here, the affordability of fashion and eclecticism of ideas is refreshing; information is spread by word-of-mouth, shops are often unmarked and short-lived, and there is little promotional activity. The shoppers there express a triumph of dressing over dress and, like children, they are spontaneous and uninhibited in their dress up games. They often reuse mass-produced commodities in their dress assemblages - for example in the decora (from 'decoration') look where masses of multifarious colourful plastic toys and objects dangle from bodies and clothes.

35 Moriyama, Japan, the Land of the Brand, Where Luxury Goods Rule. 


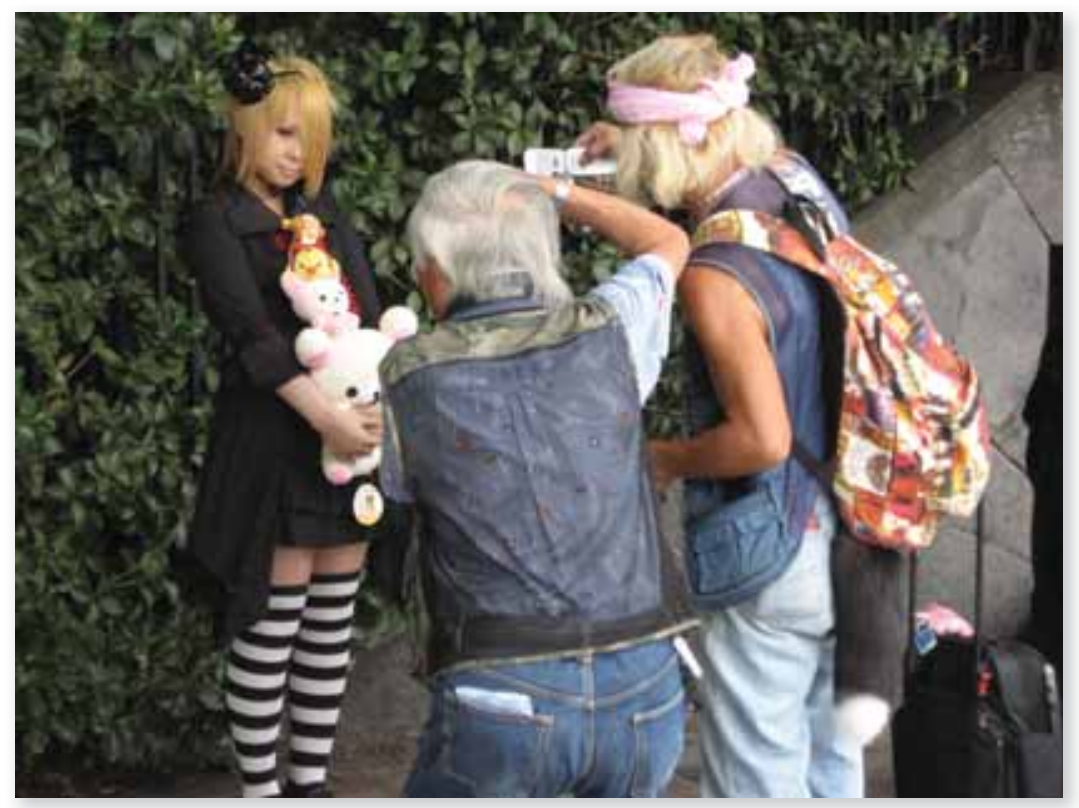

(c) Amelia Groom

The fashion of reuse challenges the values of capitalism by forming smaller systems of inclusion and refusing participation in the ongoing pursuit of new consumer products. Reselling used items is a lucrative industry in Ura-Hara, but it is different to the capitalism of first-cycle exchange because it blurs the production/consumption divide and positions the wearer as an active meaning-maker. The subjective and fortuitous nature of value and meaning was demonstrated by designer Masahiro Nakagawa with his fashion recycling venture of the early 2000s, Tokyo Recycle Project. Under his label 20471120, which had a devoted following in Harajuku, he invited people to bring him their old clothes and tell him about their associated feelings and memories. Nakagawa and his team then restructured the rejected garments into more desirable ones and returned them to their owners, undermining Japan's hyperconsumerist culture.

Mass-production and the invention of synthetic fibres were two of the earliest factors contributing to the democratisation of fashion. More recently, the counterfeit industry, eBay, recycled designer wear retail outlets in Japan like Rag Tag, and highfashion designers doing relatively cheap lines for chain stores (like Rei Kawakubo of Comme des Garçons for H\&M), have all helped the popularisation of high fashion. A multitude of cheaper products (perfumes, jeans, sports wear) also carry 'exclusive' brand names, so the aura of limited high-end production is actually widely available. One factor accounting for the recent boom in second-hand fashion is that regardless of brand name or price, fashion today is rarely exclusive. The new distinction must 
therefore come from hand-made clothes or creative and ironic uses of existing styles, to form codes that are accessible to a select group only.

In Ura-Hara, like on Omotesandō, shoppers are buying scarcity. The marginal local designers produce stock in limited numbers and exclusivity is maintained by rapid change of codes that are accessible only to those with the cultural capital to comprehend them. Being able to find and wear second-hand things in new ways is a mark of independence and a quiet resistance against the fashion system's dictums. They use experimental dressing to communicate with wider society their disillusionment with it. They are costuming their alienation and, at times, questioning the very meaning and function of dress.

\section{All Dress is Fancy Dress}

A recurring motif in Harajuku style is the donning of lingerie or corsetry on the outside. An under-garment on top of an outer-garment has lost its original function of reforming the figure and exists as an aesthetic object in its own right. It is a gesture that brings to the surface the hidden mechanics of dress objects and the fashion system. The style harks back to the early careers of Jean Paul Gaultier and Madonna, and also to the traditional Japanese dress where the open gaps under the sleeves of the kimono draw attention to the interior of the dress structure, bringing to the outside the complexity of layering that goes on beneath the surface. At the high-end of the fashion system, there is also the leading Japanese label Comme des Garçons which has often been discussed as 'deconstructivist fashion' in the way it has continually expressed an undoing of the process of construction with things like loose threads, stitching or lining on the outside of the garments and a general undone/unfinished look.

We tend to think more about how clothes are adapted to the body than the ways the body is adapted to clothes, but donning underwear as outerwear can turn this around. According to Richie the kimono is rarely designed to fit the wearer: 'the wearer is designated, as it were, to fit it. ${ }^{36}$ Similarly, in a popular footwear style in Harajuku where the shoe is shaped to separate the big and second toes, we find evidence of how clothing shapes the body. The style comes from the traditional geta and zori sandals that are worn with tabi socks that allow for the strap between the toes (construction workers, farmers, gardeners and rickshaw-pullers in Japan also wear split toe boots called jika-tabi). According to the Belgian surrealist René Magritte, 'Everything we see

36 Richie, The Image Factory: Fads and Fashions in Japan, p. 32. 
hides another thing, we always want to see what is hidden by what we see. ${ }^{37}$ Like his Le Modele Rouge series of paintings from the mid-1930s, the tabi footwear shows that our feet and the shoes we usually wear are heteromorphous.

New contexts give rise to new meanings: the dress taken from the female body and put on the male body transgresses social codes and becomes a new signifier. Similarly, in another popular Harajuku trend where the dress is taken off the body altogether and pinned on top of the wearer's clothes, the dress loses its position as a dress and questions the very meaning of fashion and clothing. Worn outside the outfit as something purely decorative, akin to jewellery, it comments on the operation of a dress for framing the body and aestheticises non-functionality. It brings into question the normalcy of the norm and asks, as George Bernard Shaw's Dunois in Saint Joan did: 'All dress is fancy dress, is it not, except our natural skins?'. Harajuku fashion, with all its excess and subversiveness, differs from mainstream style only in interpretation. The uniform of a blue suit, white shirt and tie for the salary men around Tokyo Station has no intrinsic meaning but masquerades as natural and through its social use becomes invisible. A deconstructionist approach to dressing dismantles this invisibility.

\section{New Face, New Life}

"But you are still thinking in terms of a life with a real face. The mask does not deceive and is not deceived. How about putting on a new mask, turning over a new leaf, and starting another life?" 38

As a remedy for the disfiguring burns he has suffered, Kobo Abés scientist in his 1964 novel The Face of Another builds himself an entirely new face and enjoys the instant freedom and pleasure of anonymity. The mask allows him to act without being identified and to occupy the ideal point of surveillance - the obscured tower in the centre of the panopticon. It gives him a new life, one where he sees without being seen, and in a similar vein performative fashion occupies both a hyper-visible space of spectacle, and a veiled sphere of invisibility. The more eccentric the masquerade the more attention it earns, but the more the wearer disappears behind it. Peering through the eyeholes of their literal and figurative masks, teens in Harajuku revel in their simultaneous visibility and anonymity: they are as interested in standing out in a city of twenty million, as in hiding their biological bodies from identification.

37 Torczyner, Magritte: Ideas and Images, p. 172.

38 Abé, The Face of Another, p. 163. 
Consideration of the ubiquity of masks and masked faces in historical and contemporary Japanese art and life is beyond the realms of this paper, but a brief look at the Japanese nōmen ('Nō mask') will aid our discussion on performativity. Nōmen function as a means of depriving the actor of any individuality by formalising, codifying and generalising the emotions he expresses. Ze-ami, who is attributed with founding Nō in the $14^{\text {th }}$ century, advises that even the actor performing without a mask must still keep his face completely inanimate, 'as expressionless as a mask. ${ }^{39}$ But what makes the nōmen unique amongst all other masks is in fact its uncanny ability to change expression. Rather than a fixed alternate identity they offer fluid states, albeit within set types. Whether it is the character of nubile young girl, jealous woman, passionate warrior or wise man, the mask can display amusement, grief, joy, horror, distress, determination or any other nuance of human emotion, depending on the angle at which the actor places his head and the shadows that are cast on the mask's surface.

Appearing in virtually every culture on earth, masks embody the human desire to transform the biological body via self-made images, which is the same desire that drives the strange modern phenomena we call fashion. Representing us while hiding us, masks both reveal and conceal. If we consider fashion a means for constructing and projecting an image of our perceived identity, masking can be, more than deceptive frivolity, active self-expression. Oscar Wilde's famous words 'Man is least himself when he talks in his own person. Give him a mask, and he will tell you the truth, ${ }^{40}$ are echoed by Akira Kurosawa who wrote that 'Although human beings are incapable of talking about themselves with total honesty, it is much harder to avoid the truth while pretending to be other people. ${ }^{31}$ Both used the mask as a broad analogy for the creative process.

As in many parts of the world, in Japan it was historically believed that a lady of quality had a fair complexion: it signified being rich enough to not have to work outside like the weather-beaten peasants. Upper class women were whitening their skin as early as the seventh century: they shunned sunlight, powdered their faces white, and later moved on to more complicated procedures involving bleaching and white lead, which had devastating effects. After a series of lead poisoning deaths the government banished the lead cerussite face-whitening ingredients in the nineteenth century, but many nonlead whitening products are available today as the pale face continues to be esteemed.

The value of the white face was challenged by the 'black face' subcultures that emerged in Tokyo's Shibuya district in the late 1990s, which saw the faces of young

\footnotetext{
9 Ishii, 'The Nō Theater: Mirror, Mask, and Madness', p. 29.

40 Wilde, The Artist as Critic, p. 389.

41 Kurosawa, Something Like an Autobiography, pp. 188-189.
} 
girls artificially darkened beyond recognition. The most iconic figure of the movement was Buriteri, a karisuma tenin ('charismatic salesgirl') who is said to have pioneered the ganguro ('black face') look. She named herself after the black soy sauce used on yellowtail fish (buri) in teriyaki cooking (teri). The constructedness of Buriteri's selfimage possessed an honesty that was in line with Jean Baudrillard's thoughts on makeup: 'How can one mistake this 'exceeding of nature' for a vulgar camouflaging of the truth? Only falsehoods can alienate the truth, but make-up is not false, or else ... it is falser than falsehood and so recovers a kind of superior innocence. ${ }^{42}$ Like any Japanese person with bright blond hair, she was making no attempt at authenticity. Often worn with a centimetre or two of black roots, the ganguro's hair was self-consciously fake, a reference. Like transvestites, they were more interested in the signs of femininity than any idea of naturalness.

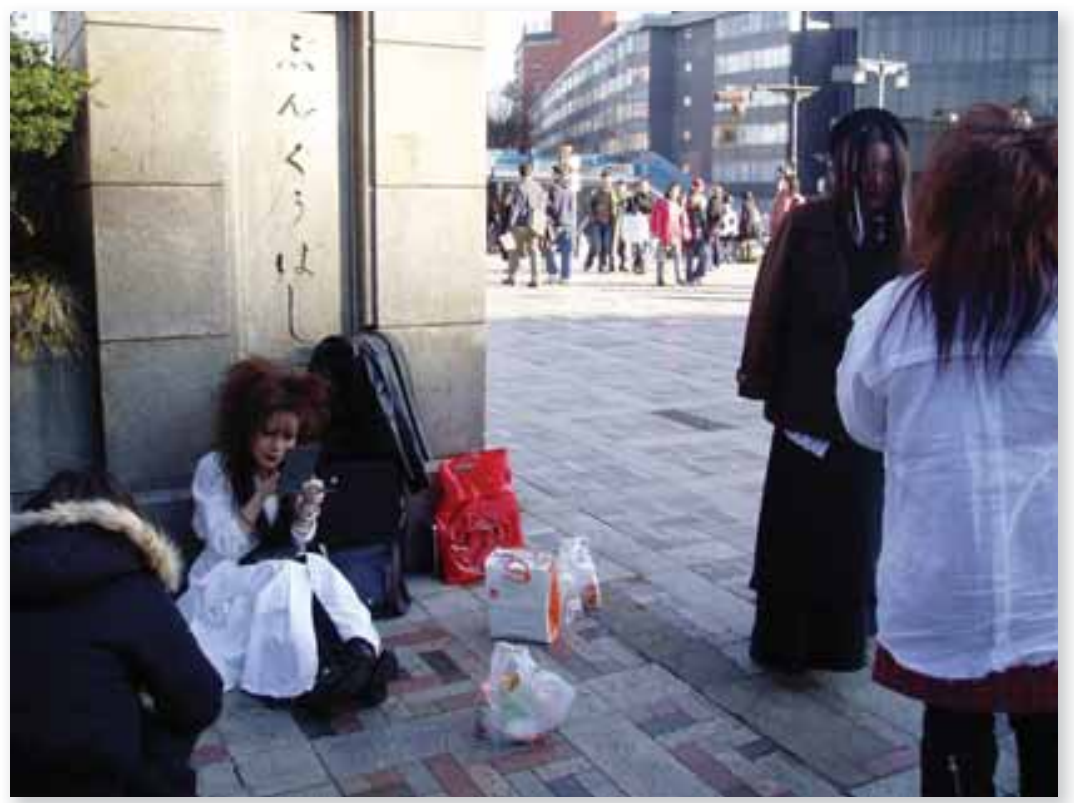

(C) Amelia Groom

An urge for blatant theatricality can be traced in many areas of Japanese art and life. Barthes was intrigued with the performativity of emptiness in the Bunraku puppetry, and the way in which it 'exhibits simultaneously the art and the labour. ${ }^{2} 3$ The wooden puppets of Bunraku have painted, mask-like faces and the three men required to manipulate each one are in clear view on stage at all times. This is much like the theatre of fashion in Harajuku, where no attempt is made to hide the artifice of it; the

42 Constable, 'Lies Make-Up and Nietzsche', p. 197.

43 Barthes, Empire of Signs, p. 54. 
labour is an integral part of the performance process and there is no 'back-stage' for preparing costumes and make-up. Because they are nearly all high-school students, Sunday is the day they come from all over the country to parade their latest creations, though on weekdays spectators can wait until after school hours for them to arrive. They often step off the train in plain clothes or school uniforms and commence preparation in full view of passers-by. There is no integrity of an original because, in Richie's words, 'as in any dramatic presentation, the only integrity is that of the performance. ${ }^{4}$

The categorisation of appearances as deceptive, frivolous, decadent or unimportant distractions or distortions of an imagined deeper existence that is beyond mere sensation dates back to Plato, whose allegory of the cave put deceiving surface image (shadows) in opposition to the 'real' essential truth (the sun). But if we depart from the idea of a total, obscured truth, we can re-examine self-decoration and find there is no reason why that which is on the outside is less genuine than what is hidden from public scrutiny. In Japan, the material and the aesthetic are given high prestige because they matter to people's internal sense of self and give substance to their external world. Fashion does not have to be seen as a superficial gloss wrapping a 'true' body or self, it can be seen as an active process of bringing things outside, an aggrandizement of an identity that is mediated with the social. Beyond narcissistic posing, the bravely fantastical, hysterically incomprehensible dressing in Harajuku can be seen as a public service that exhibits the marvellous in the mundane, embodies fantasy and optimism, and re-imagines the type of beauty that is culturally admired.

References

Abé, K., The Face of Another, trans. Dale Saunders, E. (London: Weidenfeld and Nicolson, 1966).

Bakhtin, M., Rabelias and his World (Cambridge: The MIT Press, 1968).

Barthes, R., Empire of Signs, trans. Howard, R. (New York: Hill and Wang, 1982).

Barthes, R., 'History and Sociology of Clothing: Some Methodological Observations', in Stafford, A. and Carter, M. (eds.), The Language of Fashion (New York: Berg, 2006), pp. 3-21.

Barthes, R., 'Fashion, A Strategy of Desire: Round-table Discussion with Roland Barthes, Jean Duvignaud and Henri Lefebvre' in Stafford, A. and Carter, M. (eds.), The Language of Fashion (New York: Berg, 2006), pp. 86-90.

Bourdieu, P., Distinction: a Social Critique of the Judgement of Taste (London: Harvard Uni. Press, 1984).

Bourdieu, P., 'The Metamorphosis of Tastes' in Sociology in Question (London: Sage, 1993).

44 Richie, Tokyo: A View of the City, p. 109. 
Bourdieu, P., 'Haute Couture and Haute Culture' in Sociology in Question, (London: Sage, 1993).

Butler, J., Gender Trouble - Feminism and the Subversion of Identity (New York and London: Routledge, 1999).

Carlyle, T., Sartor Resartus (London: J. M. Dent \& Sons, 1973).

Constable, C., 'Lies Make-Up and Nietzsche' in Bruzzi, S. and Gibson, P. C. (eds.), Fashion Cultures: Theories, Explorations and Analysis (London and New York: Routledge, 2000).

Cox, R., The Zen Arts: An Anthropological Study of the Culture of Aesthetic Form in Japan, (London: Royal Asiatic Society Books, Routledge, 2003).

Craik, J., Faces of Fashion: Cultural Studies in Fashion (New York: Routledge, 1994).

Craik, J., 'The Cultural Politics of the Uniform' in Fashion Theory, vol. 7, no. 2 (2003), pp. 127-148.

De Certeau, M., The Practice of Everyday Life (Berkeley and Los Angeles: University of California Press, 1984).

Foucault, M., The History of Sexuality: An Introduction, trans. Hurley, R. (New York: Vintage Books: A Division of Random House, 1976).

Foucault, M., 'Lecture Two' in Gordon, C. (ed.), Power/Knowledge (New York: Pantheon, 1980).

Hebdige, D., Subculture: The Meaning of Style (New York: Routledge, 1979).

Ishii, M., 'The Nō Theater: Mirror, Mask, and Madness' in Comparative Drama 28:1 (Spring 1994), pp. 43-66.

Kawamura, Y., 'Japanese Teens as Producers of Street Fashion' in Current Sociology, vol. 54, no. 5 (2006), pp. $784-801$.

Kinsella, S., Cuties In Japan (1995). Retrieved 7 August 2007, from http://ebasic.easily.co.uk/04F022/036051/Cuties.html.

Kinsella, S., 'Japanese Highschool Girl Brand' in Pavitt, J. (ed.), Brand. New (London: V\&A Publications, 2000), pp. 104-5.

Kinsella, S., 'What's Behind the Fetishism of Japanese School Uniforms?' in Fashion Theory, vol. 6, no. 2 (2000), pp. 215-238.

Kurosawa, A., Something Like an Autobiography (New York: Knopf, 1982).

Moriyama, N., Japan, the Land of the Brand, Where Luxury Goods Rule (2005). Retrieved 1 July 2007, from www.japansociety.org/corporate/event_corp_note.cfm?id_note=507508683.

McCormick, J. P., 'Japan: The Mask and the Mask-Like Face' in The Journal of Aesthetics and Art Criticism, vol. 15, no. 2 (1956), pp. 198-204.

McVeigh, B., Wearing Ideology: State, Schooling and Self-Presentation in Japan, (Oxford and New York: Berg, 2000).

Natsume, S., I Am A Cat vol. 2, trans. Ito, A. and Wilson, G. (Vermont/Japan: Charles E. Tuttle Co., 1979).

Polhemus, T., Street Style: From Sidewalk to Catwalk (London: Thames and Hudson, 1994).

Richie, D., Tokyo: A View of the City (London: Reaktion Books, 1999).

Richie, D., The Image Factory: Fads and Fashions in Japan (London: Reaktion Books, 2003).

Spindler, A. M., 'Do You Otaku?' New York Times (February 24 2002). Retrieved 18 October 2007, from http://query.nytimes.com/gst/fullpage.html?res=9C00E6D8113DF937A15751C0A9649C8B63. 
New Voices Volume 4

Torczyner, H., Magritte: Ideas and Images, trans. Millen, R. (New York: Harry N. Abrams, 1977).

Wilcox, C., Vivienne Westwood (London: V\&A Publications, 2004).

Wilson, E., 'Feminism and Fashion', in Welters, L. and Lillethun, A. (eds.), The Fashion Reader, (Oxford and New York: Berg, 1995), pp. 203-212.

Wilde, O., 'The Artist as Critic' in Ellmann, R. (ed.), Critical Writings of Oscar Wilde (New York: Random House, 1968).

Woolf, V., Orlando: A Biography (London: The Hogarth Press Ltd., 1970). 